\title{
Impact of International Accreditation in Pharmacy Education: Pharmacy School Students' Perspective
}

\author{
Rula Darwish ${ }^{1, \star}$, Mohammad Saleh $^{2}$, Khawlah Ammar $^{3}$, Mohammad AIMasri $^{4}$ \\ 1'Department of Pharmaceutics and Pharmaceutical Technology, School of Pharmacy, The University of Jordan, Amman, JORDAN. \\ 2Biopharmaceutics and Clinical Pharmacy, School of Pharmacy, The University of Jordan, JORDAN. \\ ${ }^{3}$ King Hussein Cancer Center, Survey Unit, Amman, JORDAN. \\ ${ }^{4}$ School of Medicine, The University of Jordan, Amman, JORDAN.
}

\begin{abstract}
Background: The accreditation of undergraduate Pharmacy Schools is an important quality assurance process. In spite of the widespread adoption of international accreditation processes and an increasing attention on accreditation as a mechanism to ensure minimum standards are met, there is little evidence to support their effectiveness. Objectives: To assess the School of Pharmacy students' and new graduates' views on the impact of international certification on their education and career and whether this experience could be used to improve the pharmacy education program and environment. Methods: A descriptive cross-sectional survey was used with six major themes focusing on, student-faculty-administration relationships, student support, learning environment and pedagogical methods, library and electronic learning resources, experiential training and the educational program as a whole. Four hundred forty-nine participants completed the survey from which fifty-two were new graduate. Results: School of Pharmacy students' and new graduates have positive perception of international certification. Participants agreed that the certification process has been beneficial in terms of enhancing the overall program quality, the quality of education, learning environment, program structure, students support as well as enhancing opportunities. Misperceptions, however, existed about potential opportunities available to graduates of internationally certified programs. Conclusion: This research carries value to university administrators and education policymakers in terms of improving regulations and targeting students to ensure promising academic environment and improve the image of the educational institutions.
\end{abstract}

Key words: Accreditation, International certification, Pharmaceutical education, Students, Pharmacy, Learning environment.

\section{INTRODUCTION}

Recently, international accreditation has captured interests and concerns of Schools of Pharmacy. While it is a voluntary process, it would ensure that education provided by schools meets globally acceptable levels of quality. School's possession of accreditation status can be very reassuring to the community, researchers, stakeholders and job market. In spite of the widespread adoption of international accreditation processes and an increasing attention on accreditation as a mechanism to ensure meeting standards, there is little evidence supporting their effectiveness. As more schools and countries adopt standards of international accrediting bodies, it is important to consider the challenges facing students and graduates and probably adopt educational reform initiatives. Accreditation Council for pharmacy Education offers through International Services Program (ISP) professional degree program certification worldwide to stakeholders who seek guidance related to quality assurance and advancement of pharmacy education and thus assist schools of pharmacy to improve the quality of their degree program. The major focus of this accrediting body is on supporting quality improvement efforts and initiatives of schools of pharmacy.
Submission Date: 02-08-2020; Revision Date: 07-02-2021; Accepted Date: 12-04-2021

DOI: 10.5530/ijper.55.2s.107 Correspondence:

Prof. Rula M Darwish Department of Pharmaceutics and Pharmaceutical Technology, School of Pharmacy, The University of Jordan, Amman, JORDAN.

Phone no: +96-2795558089 Email id: rulamdarwish@yahoo. com

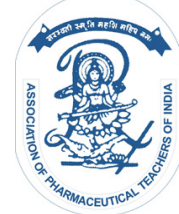

www.ijper.org 
The University of Jordan was the first school in Jordan to apply for and receive ACPE Certification of its BS and Pharm D programs using the ACPE International Quality Criteria. ${ }^{1}$ As a result, several important progresses occurred including improvements related to: experiential training, teaching methodologies, assessment methods, students' involvement in different activities in addition to better documentation processes. Students' involvement and assessment of changes happening in the school as a result of accreditation is very important. Feedback provided by students can strengthen the accreditation process. Students' opinion would also strengthen the institution by providing feedback to faculty members and administrators at levels students know best. Much of university-specific education research has been conducted on student engagement. ${ }^{2,3}$ However, little investigation was performed on students' engagement within a college rather than to its greater university, especially when that college must adhere to additional differing certification standards. Students' opinion and outcomes can be used as a guide for future improvement. Moreover, students' belief that the program, teaching methods, academic counseling, faculty accessibility, facilities and library are improving would lead to more self-assurance and may encourage to developing self-directed learning qualities which are important to the growth and success of the pharmacy profession, beginning with the education of pharmacy students. The 2016 ACPE Accreditation Standards expressed the importance of schools integrating teaching, learning methods and outcome statements that help students transition from dependent to active, self-directed lifelong learners. ${ }^{4}$ As for teaching methodologies, ACPE standards in 2007 encouraged use of active learning strategies and other high level pedagogical strategies. Later ACPE 2016 standards advocate for teaching and learning methods that actively engage learners, promote self-directed learning and foster collaborative learning. This work investigated the impact and value of the international accreditation process on students and new graduates of School of Pharmacy which has been internationally certified by the ACPE in terms of their confidence in their education and their belief that employers can trust that graduates of internationally certified programs are prepared to enter the workforce. Furthermore, the work focused on participants' opinions on major areas which can directly or indirectly affect the education quality. This work will pave the way for our potential future study to compare students' perceptions of the improvements achieved after certification for all pharmacy schools in Jordan.

\section{MATERIALS AND METHODS}

\section{Study design and study tool}

A descriptive cross-sectional survey was used between February and May 2017. Six major themes were focused on namely; student-faculty-administration relationships, student support, learning environment, library and electronic learning resources, experiential training and the educational program as a whole. A structured survey was developed by reviewing relevant literature used previously in similar studies. ${ }^{5,6}$ An expert committee of faculty members from different departments, some were involved in the certification process others were not, to assure absence of bias, designed the survey and tailored it to the school's setting to assure its applicability. Content validity of the tool was assessd by experts and was considered valid then was translated into Arabic. Validity of the translation was assured by consulting personnel who are fluent in both languages. Furthermore, it was field-tested on a pilot sample of 25 students (about $5 \%$ of the target sample) to clarify any ambiguities. The survey comprised a total of 46 closed-ended questions divided into six sections. The first part covered participants' demographic data including education level and major. The first section focused on student-facultyadministration relationships, administration awareness of students' problems and their responses to students' concern. The second section covered students' support and learning environment. The third section was about library and electronic learning resources. The fourth part focused in the educational program as a whole including academic and personal counseling. The learning environment and its suitability and improvement was covered in the fifth section. While the last section discussed the educational program as a whole and changes that were felt by students after certification.

\section{The study participants and study sample}

School of Pharmacy students in the University of Jordan from third until sixth year whose numbers amounted to nearly 1406 students in 2017, in addition to 52 new graduates. Participants were selected if they were in the school before and after the certification review of the program. Based on Best Practices for Survey Research Reports, ${ }^{7}$ Implications of Target Participants, Probability Sampling and Response Rate, the minimum needed sample size to represent our sample is 306 students, our sample included 449 participants. Students were asked to complete electronic surveys at the beginning of different classes after obtaining the instructors' permission. The link was opened for 2 lectures randomly selected for each year, the sample was 397 from our targeted participants $(n=1406)$ which is a sufficient number (supposing $2 \%$ 
of students were absent). ${ }^{8}$ Completed anonymized surveys were collected at the end of the classes. New graduates, some of them were students at the time of the certification process, filled 52 surveys.

\section{Data analysis}

Descriptive and reliability analysis was performed using SPSS v.19. Associations between different responses or demographic variables were conducted using Chi-square test. $P$-values of 0.05 or less were considered significant. Questions were grouped as previously mentioned sections and answers options were five Likert Scale; strongly agree, agree, neutral (or unable to comment for certain questions), disagree, strongly disagree. To simplify reporting, strongly agree and agree were considered as one group and strongly disagree and disagree considered the same too.

Questionnaire results were compared between BS students and Pharm D students. For each questionnaire response (Figures 1-4), a contingency table was constructed from two variables, namely student major (BS or Pharm D) and response to questionnaire question (agree, nor opinion, or disagree). Chi-square $p$-value was then computed using SPSS. Proportion for each response were then compared based on student major with appropriate adjustment of the $p$-value using bonferroni method.

\section{RESULTS AND DISCUSSION}

Students enroll at a school to pursue successful educational experiences and credentials. Students need access to professionally productive faculty, healthy environment and adequate resources. International certification should help in achieving satisfaction and improve institutional performance. Satisfied -students are expected to be more motivated to improve their overall performance thus might become active learners rather than dependent ones. Guidelines and Standards set by ACPE emphasizes the significance of schools integrating teaching and learning methods and outcome statements that will lead students to change from dependent to active, self-directed lifelong learners. In this students and new graduates were asked whether they agreed or not on positive changes that happened in their school as a result of the international. A reliability analysis was carried out to assess the internal consistency of the questionnaire. Cronbach's alpha computed for the current questionnaire was 0.957 which indicates excellent reliability. ${ }^{9}$ One hundred seventy-one BS (38.8\%) and $278(61.9 \%)$ Pharm D students (age 21-25years old) were involved in the study. Figure 1; A showed that almost three quarters $(73.9 \%)$ of participants agreed that certification improved their confidence in their education with $(73.1 \%)$ agreeing that the certification improved the quality of education delivered by school. As for participants agreeing that changes happened in employers trust in graduates of accredited programs and whether they met educational requirements necessary to enter the workforce and enhance the mobility, were $78.6 \%$ and $63.5 \%$ respectively. This is probably because they believe that employers understood that school seeking international certification would emphasize on competence and professionalism of their pharmacy graduates. This was in agreement with findings by Sealy et al. ${ }^{9}$ which showed that feedback from key stakeholders on the quality of pharmacy graduates is above average, however additional work is needed to address some deficiencies. Pharmacy students could be required to complete a series of studies and training to address shortcomings and to narrow gaps found between actual working environment and their education. ${ }^{9}$ Therefore, School of Pharmacy should emphasize on learning goals and articulate academic standards to meet stakeholders' expectations as well as preparing students to be lifelong learners and ensuring their readiness for continuing professional development (CPD). Richard O'Brocta et al. ${ }^{10}$ Showed that integrating CPD requirements for students in schools of pharmacy is important to students'

A

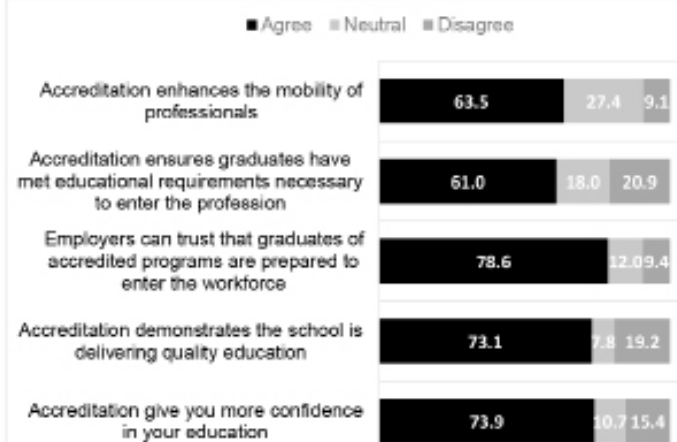

B

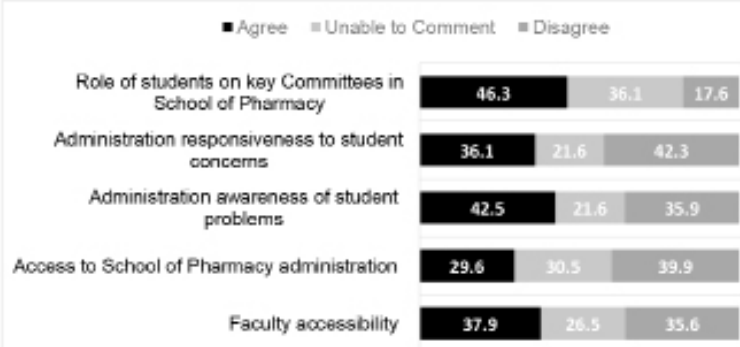

Figure 1: Accreditation Impact on Employment from Students' Point of View; B: Students' Responses Percentages for Student-Faculty-Administration Relationships. 
development of life-long learning skills. Consequently, it is recommended that School of Pharmacy start building the culture of CPD from the early years of study.

Another challenge that was revealed in this study was related to student -faculty and student -administration relationship. Figure 1; B showed that participants who agreed that accessibility of faculty and administration improved after certification were only $37.9 \%$ and $29.6 \%$ respectively. A percentage of $42.5 \%$ of participants agreed that administration awareness of student problems improved however, only $36.1 \%$ agreed that administration responsiveness to student concerns improved after certification. About $46.3 \%$ of participants agreed that the role of students on key committees improved while $17.6 \%$ didn't agree. These low percentages are alarming, literature has shown that interactions between faculty and students in and outside classrooms to have significant impact on students. ${ }^{11}$ ACPE Standards acknowledge the importance of faculty engagement and embraces its effects on educational outcomes. ${ }^{4}$ Thus academic orientation programs designed to help students understand the nature of the relationship between students and faculty in college and designed to help students become integrated into academic life in college may be important as suggested by Terenzini and Wright. ${ }^{12}$ Figure 2 showed that almost half of the participants $(49.0 \%)$ agreed that availability of tutorials help improved after certification and although 46.5\% agreed that academic counseling adequacy improved after certification, only $31 \%$ and $27.4 \%$ agreed that counseling availability and adequacy for personal problems have improved, respectively. As for counseling confidentiality for personal problems, only $25.8 \%$ agreed that it has improved while $21.8 \%$ did not agree. About $41 \%$ agreed that counseling availability and adequacy for careers has improved while about one fifth disagreed. As for informative and educational activities that aimed at preventing student mistreatment, $40.3 \%$ agreed that this has improved and equal numbers (one third) disagreed or were unable to comment. A percentage of $44.8 \%$ agreed that appropriateness of student advancement and graduation policies have improved, whereas 35.6\% agreed that appropriateness of policies and procedures for disciplinary action improved. Only $32.1 \%$ agreed that confidentiality of student records improved, while 53.7\% were unable to comment. Around one third agreed that availability of student records for review and challenge improved, while $45.2 \%$ were unable to comment. Participants agreeing on improvement regarding diversity of the student body were $40.5 \%$ and almost half agreed that faculty diversity improved after certification. These generally indicates positive effect of accreditation with

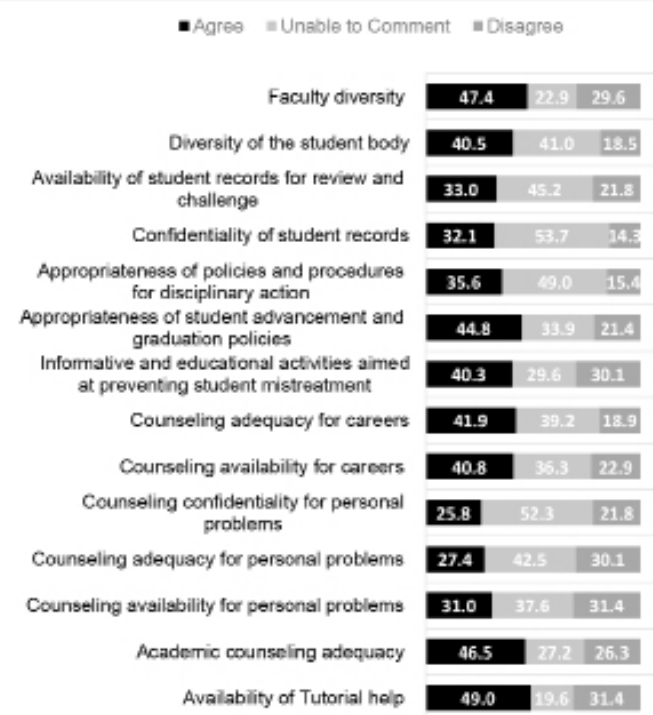

Figure 2: Responses Percentages of Students for Student Support.

a room for modification. Another important aspect of student experiences is the learning environment. ${ }^{13}$ It includes physical settings comprising learning and social spaces on campus. Studies ${ }^{14}$ suggest that good learning environment is a major asset in students' learning. Results in Figure 3; Indicated that 56.3\% of participants agreed that sufficiency of classrooms, labs and testing facilities has improved after certification; however, about one third disagreed. As for sufficiency of student study space $47.2 \%$ agreed that it improved. Only $27.2 \%$ agreed that sufficiency of student relaxation space improved while $58.1 \%$ disagreed. About half the participants $(51.9 \%)$ agreed that adequacy of systems for personal safety and security improved. These results reflected the positive effect of certification process on the learning environment. Nowadays medical care is provided in electronic, web-networked evidence environment, with massive range of online information services. This suggests that students should be trained on how to use this information and find solutions for health care. Figure 3; B demonstrated that only 31.0\% agreed that availability, quality of library services and availability together with adequacy of computer learning resources improved after certification; an equal percentage of $34.5 \%$ disagreed or were unable to comment. An even lower percentage (28.5\%) agreed that adequacy of library holdings and instructional resources improved, while 36.3\% disagreed. However, 51.9\% agreed that efficiency of school web sites for learning improved after certification. The study findings are in agreement with that of Nina et al. ${ }^{15}$ Which further emphasized that not only providing resources is important but also guidance 

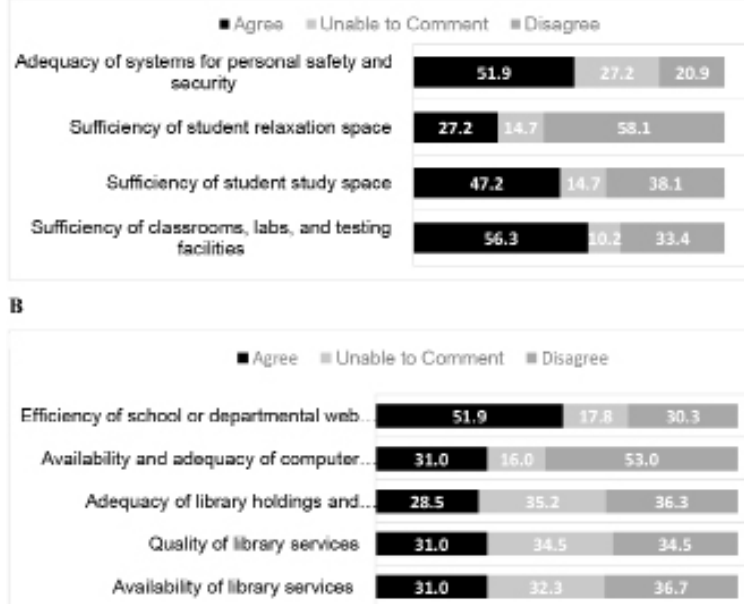

Figure 3: Responses Percentages of Students on Learning Environment B: Responses Percentages of Students on Experiential Training.

in using the library assets and services is necessary to help students meet the requirements. Without proper knowledge of accessing the information sources whether electronic or printed students are susceptible to overloaded and sometimes redundant information.

It is important to graduate well trained pharmacists who are able and ready to accept responsibility and accountability for drug therapy management. Figure 4; A revealed that more than half the participants (55\%) agreed that presence of preceptors at experiential sites, responsible for coordinating students' activities, in addition to training them on the required competencies in the simulation pharmacy has improved after certification. Moreover, $62.8 \%$ participants agreed that there was an improvement in experiential activities to include at least two different types of contemporary pharmacy settings. Results are in agreement with that by Kerry et al. ${ }^{16}$ Which showed that faculty involvement and collaboration with pharmacists at practice sites is desired and should continue in upcoming years. Also the responses emphasized the importance of training at different settings, with community pharmacy being one of these sites since the majority of graduates will practice in this setting. ${ }^{17}$ This is in agreement with results of research done on student in South Korea which emphasized the importance of community pharmacy as a site of training. ${ }^{18}$ Results in Figure 4; B showed that around half of the participants (51\%) agreed that quality of the educational program improved after certification and $27 \%$ disagreed. As for the quality of basic science and clinical instruction, $40.5 \%$ agreed that it was improved. The percentage of participants who agreed that appropriateness of teaching methods and
A

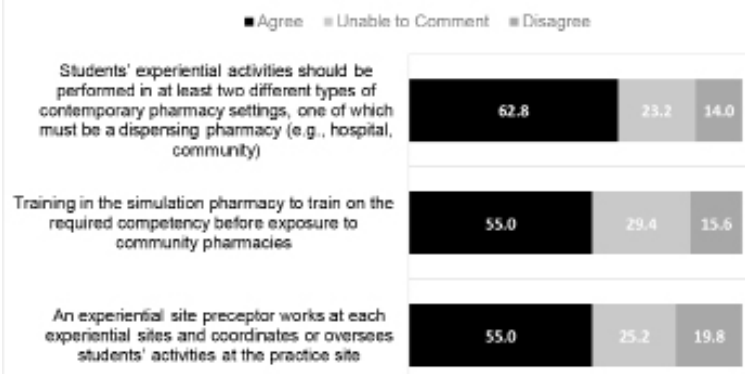

B

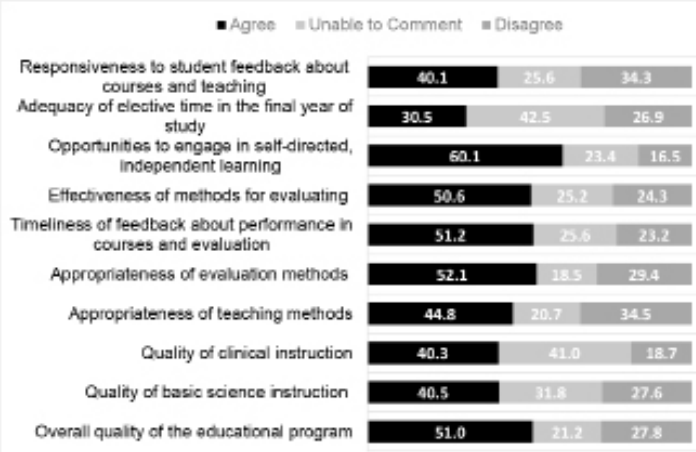

Figure 4: Responses Percentages of Students on Experiential Training B: Responses Percentages of Students on Educational Program as a Whole.

evaluation methods improved after certification was $44.8 \%$ and $52.1 \%$ respectively. Participants agreeing that timelines of feedback about performance in courses and evaluation had improved were $51.2 \%$. Participants who agreed that effectiveness of methods for evaluating and opportunities to engage in self-directed, independent learning improved were $50.6 \%$ and $60.1 \%$ respectively. However, a lower percentage of participants agreed that adequacy of elective time in the final year of study improved after certification (30.5\%). Additionally, participants who agreed that responsiveness to student feedback about courses and teaching improved after certification were $40.1 \%$. It seems that students favor modernization of the curriculum and making it more oriented towards pharmacy practice and clinical pharmacy, this is in agreement with a study by El-Sayed $e t$ al. ${ }^{19}$ Which showed that students were aware of changes within the profession of pharmacy and were eager to see changes within their own country. As for teaching methodology, again there was agreement between our finding and that of El-Sayed et al. ${ }^{19}$ Where aspects of current teaching methodology were still valued by some students although more improvement is needed in this area. Thus curriculum development should be evolutionary rather than revolutionary and modern teaching methods should always be introduced alongside, rather than replace, effective traditional methods. ${ }^{20,21} \mathrm{~A}$ 
lower percentage of participants agreed that certification improves responsiveness to student feedback about courses and teaching. These findings suggest that schools should work more on the improvement of time management and transparency with regard to student feedback about courses and teaching.

In general, it seems that students in all year's showed some degree of satisfaction with most criteria. However, some criteria revealed that new graduates and students in their senior years (22-23 years old) are less satisfied than those in $3^{\text {rd }}$ and $4^{\text {th }}$ years (20-21 years old). Perhaps because senior students would have had a greater proportion of their years of study in the program that were not positively influenced by certification. Also they were more exposed to training and job market thus they were able to see the gaps between practice and what they have been taught. Results in Table 1 showed significant difference in administration awareness of student problems and the role of students on key committees in school of Pharmacy after certification with $p=0.001$ and $<0.0001$ respectively. Significance was also noticed in availability of tutorial help $(p=0.003)$ as well as in counseling and improvement of policies / procedures for disciplinary and student's mistreatment $(p<0.001)$. Significance was similarly observed in perception to improvement in experiential training $(p<0.001)$ and in responsiveness to students' feedback about courses and teaching $(p=0.003)$. Also in the effect of international accreditation on quality of clinical instruction $(p=$ 0.0001), quality of basic science instruction $(p=$ $0.007)$, academic counseling adequacy ( $p=0.007 ; 0006$ respectively),counseling availability and adequacy for careers $(p=0.0001)$, appropriateness of policies and procedures for disciplinary action $(p=0.001)$ and in overall quality of the educational program $(\phi=0.0001)$. Comparing questionnaire results based on student major for all items presented in Figures 1-4 resulted in significant differences in the response to four questions as displayed in Table 2. There were no significant differences in the response of other questions. Around 46\% of Pharm $\mathrm{D}$ student agreed that quality of clinical instructions improved after accreditation was significantly different from a percentage of $30 \%$ in BS students. The difference is expected because Pharm D students has more than one academic year of clinical training compared to 3 credit hours for BS students. Hence, the effect of accreditation on quality of clinical instructions is expected to be more pronounced by Pharm D students. The improvement in availability and quality of library services after accreditation was more pronounced by Pharm D students compared to BS student. Online library resources such as AcessPharmacy, UpToDate,
Lexicomp, and Pubmed are more commonly used by Pharm D students during their course work compared to BS student. Hence, it is expected for the Pharm D students to notice an improvement in library services compared to BS students.

The most important limitation of the present study is that the design of the questionnaire was driven by the ACPE guidelines. The present study did not address other international accreditation bodies such as the Canadian Council for Accreditation of Pharmacy Programs (CCAPP) and Australian Pharmacy Council (APC). ${ }^{22}$ This limitation is attributed to the lack of data from Jordan regarding international accreditation programs other than the ACPE. Presently, pharmacy schools in Jordan has only applied to ACPE as an international accreditation organization. Nationally, the first pharmacy school in Jordan was accredited by the ACPE inn 2016. Currently, there are 5 pharmacy schools accredited by the ACPE in Jordan. ${ }^{23}$ None of the Pharmacy schools in Jordan has applied to an international accreditation program other than the ACPE. Another limitation is the need to analyse data on the basis of class of students in course. In addition, it is recommended to include perception of alumni.

\section{CONCLUSION}

School of pharmacy students' agreed that certification process generally has been beneficial in terms of enhancing the overall program quality, quality of education, learning environment, program structure, support for students, as well as enhancing opportunities. It is important to recognize challenges facing graduates and adopt educational reform initiatives. The findings can be used to assist in formulating regulations and encourage emphasizing on students to ensure their trust in their schools and positive views of their careers. Bridging the gaps between School and stakeholders' expectations, and balancing theoretical and practical exposure within the curriculum is essential. The present manuscript gives a broad overview of six themes that includes: student-faculty-administration relationships, student support, learning environment and pedagogical methods, library and electronic learning resources, experiential training and the educational program as a whole. Future work concerns deeper analysis of each of the themes included presently.

\section{ACKNOWLEDGEMENT}

The authors are grateful to the Deanship of Scientific Research, The University of Jordan, Amman - Jordan and for the School of Pharmacy for the support of this work. 


\begin{tabular}{|c|c|c|c|c|c|c|c|c|c|}
\hline & & $\underset{\mathrm{N}}{\text { Agree }}$ & $\%$ & $\begin{array}{c}\text { No } \\
\text { opinion }\end{array}$ & $\%$ & $\begin{array}{c}\text { Disagree } \\
\mathbf{N}\end{array}$ & $\%$ & Total & $p$ value \\
\hline \multirow{3}{*}{$\begin{array}{c}\text { Employers can trust that graduates of } \\
\text { accredited programs are prepared to enter } \\
\text { the workforce. }\end{array}$} & Fresh & 28 & 53.8 & 13 & 25.0 & 11 & 21.2 & 52 & \multirow{3}{*}{0.001} \\
\hline & $3 \& 4$ & 102 & 49.3 & 40 & 19.3 & 65 & 31.4 & 207 & \\
\hline & $5 \& 6$ & 61 & 32.1 & 44 & 23.2 & 85 & 44.7 & 190 & \\
\hline \multirow{3}{*}{$\begin{array}{l}\text { Administration awareness of student } \\
\text { problems improved after accreditation }\end{array}$} & Fresh & 28 & 53.8 & 13 & 25.0 & 11 & 21.2 & 52 & \multirow{3}{*}{0.001} \\
\hline & $3 \& 4 \%$ & 102 & 49.3 & 40 & 19.3 & 65 & 31.4 & 207 & \\
\hline & $5 \& 6 \%$ & 61 & 32.1 & 44 & 23.2 & 85 & 44.7 & 190 & \\
\hline \multirow{3}{*}{$\begin{array}{l}\text { Availability of Tutorial help improved after } \\
\text { accreditation }\end{array}$} & Fresh & 30 & 57.7 & 6 & 11.5 & 16 & 30.8 & 52 & \multirow{3}{*}{0.003} \\
\hline & $3 \& 4$ & 117 & 56.5 & 35 & 16.9 & 55 & 26.6 & 207 & \\
\hline & $5 \& 6$ & 73 & 38.4 & 47 & 24.7 & 70 & 36.8 & 190 & \\
\hline \multirow{3}{*}{$\begin{array}{l}\text { Training in the simulation pharmacy to train } \\
\text { on the required competency before exposure } \\
\text { to community pharmacies }\end{array}$} & Fresh & 36 & 69.2 & 11 & 21.2 & 5 & 9.6 & 52 & \multirow{3}{*}{0.001} \\
\hline & $3 \& 4$ & 104 & 50.2 & 78 & 37.7 & 25 & 12.1 & 207 & \\
\hline & $5 \& 6$ & 107 & 56.3 & 43 & 22.6 & 40 & 21.1 & 190 & \\
\hline \multirow{3}{*}{$\begin{array}{l}\text { Appropriateness of evaluation methods } \\
\text { improved after accreditation }\end{array}$} & Fresh & 38 & 73.1 & 4 & 7.7 & 10 & 19.2 & 52 & \multirow{3}{*}{0.006} \\
\hline & $3 \& 4$ & 109 & 52.7 & 43 & 20.8 & 55 & 26.6 & 207 & \\
\hline & $5 \& 6$ & 87 & 45.8 & 36 & 18.9 & 67 & 35.3 & 190 & \\
\hline \multirow{3}{*}{$\begin{array}{c}\text { Responsiveness to student feedback } \\
\text { about courses and teaching improved after } \\
\text { accreditation }\end{array}$} & Fresh & 30 & 57.7 & 9 & 17.3 & 13 & 25.0 & 52 & \multirow{3}{*}{0.003} \\
\hline & $3 \& 4$ & 86 & 41.5 & 61 & 29.5 & 60 & 29.0 & 207 & \\
\hline & $5 \& 6$ & 64 & 33.7 & 45 & 23.7 & 81 & 42.6 & 190 & \\
\hline \multirow{3}{*}{$\begin{array}{l}\text { Role of students on key Committees } \\
\text { in School of Pharmacy improved after } \\
\text { accreditation }\end{array}$} & Fresh & 32 & 61.5 & 8 & 15.4 & 12 & 23.1 & 52 & \multirow{3}{*}{0.0001} \\
\hline & $3 \& 4$ & 110 & 53.1 & 77 & 37.2 & 20 & 9.7 & 207 & \\
\hline & $5 \& 6$ & 66 & 34.7 & 77 & 40.5 & 47 & 24.7 & 190 & \\
\hline \multirow{3}{*}{$\begin{array}{l}\text { Overall quality of the educational program } \\
\text { improved after accreditation }\end{array}$} & Fresh & 33 & 63.5 & 7 & 13.5 & 12 & 23.1 & 52 & \multirow{3}{*}{0.003} \\
\hline & $3 \& 4$ & 118 & 57.0 & 44 & 21.3 & 45 & 21.7 & 207 & \\
\hline & $5 \& 6$ & 78 & 41.1 & 44 & 23.2 & 68 & 35.8 & 190 & \\
\hline \multirow{3}{*}{$\begin{array}{l}\text { Quality of basic science instruction improved } \\
\text { after accreditation }\end{array}$} & Fresh & 26 & 50.0 & 12 & 23.1 & 14 & 26.9 & 52 & \multirow{3}{*}{0.007} \\
\hline & $3 \& 4$ & 97 & 46.9 & 64 & 30.9 & 46 & 22.2 & 207 & \\
\hline & $5 \& 6$ & 59 & 31.1 & 67 & 35.3 & 64 & 33.7 & 190 & \\
\hline \multirow{3}{*}{$\begin{array}{l}\text { Quality of clinical instruction improved after } \\
\text { accreditation }\end{array}$} & Fresh & 33 & 63.5 & 8 & 15.4 & 11 & 21.2 & 52 & \multirow{3}{*}{0.000} \\
\hline & $3 \& 4$ & 71 & 34.3 & 117 & 56.5 & 19 & 9.2 & 207 & \\
\hline & $5 \& 6$ & 77 & 40.5 & 59 & 31.1 & 54 & 28.4 & 190 & \\
\hline \multirow{3}{*}{$\begin{array}{l}\text { Appropriateness of evaluation methods } \\
\text { improved after accreditation }\end{array}$} & Fresh & 38 & 73.1 & 4 & 7.7 & 10 & 19.2 & 52 & \multirow{3}{*}{0.006} \\
\hline & $3 \& 4$ & 109 & 52.7 & 43 & 20.8 & 55 & 26.6 & 207 & \\
\hline & $5 \& 6$ & 87 & 45.8 & 36 & 18.9 & 67 & 35.3 & 190 & \\
\hline \multirow{3}{*}{$\begin{array}{l}\text { Adequacy of elective time in the final year of } \\
\text { study improved after accreditation }\end{array}$} & Fresh & 21 & 40.4 & 11 & 21.2 & 20 & 38.5 & 52 & \multirow{3}{*}{0.000} \\
\hline & $3 \& 4$ & 59 & 28.5 & 115 & 55.6 & 33 & 15.9 & 207 & \\
\hline & $5 \& 6$ & 57 & 30.0 & 65 & 34.2 & 68 & 35.8 & 190 & \\
\hline
\end{tabular}

*Fresh=fresh graduates; $3 \& 4=$ third and fourth year students; $5 \& 6=$ fifth and sixth year 


\begin{tabular}{|c|c|c|c|c|c|c|}
\hline \multicolumn{3}{|c|}{ BSc in Pharmacy Pharm D } & \multicolumn{2}{|c|}{ Student's major* } & \multirow{2}{*}{$\begin{array}{l}\text { Total } \\
181 \\
\end{array}$} & $p$-value ${ }^{* *}$ \\
\hline \multirow{6}{*}{$\begin{array}{l}\text { Quality of clinical instruction } \\
\text { improved after accreditation }\end{array}$} & \multirow{2}{*}{ 1-Agree } & Count & $52 a$ & $129_{b}$ & & \multirow{6}{*}{0.003} \\
\hline & & $\%$ within Student's major & $30.40 \%$ & $46.40 \%$ & $40.30 \%$ & \\
\hline & \multirow{2}{*}{ 2- No Opinion } & Count & $84_{a}$ & $100_{b}$ & 184 & \\
\hline & & $\%$ within Student's major & $49.10 \%$ & $36.00 \%$ & $41.00 \%$ & \\
\hline & \multirow{2}{*}{ 3- Disagree } & Count & $35 a$ & $49_{a}$ & 84 & \\
\hline & & $\%$ within Student's major & $20.50 \%$ & $17.60 \%$ & $18.70 \%$ & \\
\hline \multirow{6}{*}{$\begin{array}{l}\text { Informative and educational } \\
\text { activities aimed at preventing } \\
\text { student mistreatment improved } \\
\text { after accreditation }\end{array}$} & \multirow{2}{*}{ 1-Agree } & Count & $70_{a}$ & $1111_{a}$ & 181 & \multirow{6}{*}{0.011} \\
\hline & & $\%$ within Student's major & $40.90 \%$ & $39.90 \%$ & $40.30 \%$ & \\
\hline & \multirow{2}{*}{ 2- No Opinion } & Count & $622_{a}$ & $71_{b}$ & 133 & \\
\hline & & $\%$ within Student's major & $36.30 \%$ & $25.50 \%$ & $29.60 \%$ & \\
\hline & \multirow{2}{*}{ 3- Disagree } & Count & $39_{a}$ & $96_{b}$ & 135 & \\
\hline & & $\%$ within Student's major & $22.80 \%$ & $34.50 \%$ & $30.10 \%$ & \\
\hline \multirow{6}{*}{$\begin{array}{l}\text { Availability of library services } \\
\text { improved after accreditation }\end{array}$} & \multirow{2}{*}{ 1-Agree } & Count & $42_{a}$ & $97_{\mathrm{b}}$ & 139 & \multirow{6}{*}{0.016} \\
\hline & & $\%$ within Student's major & $24.60 \%$ & $34.90 \%$ & $31.00 \%$ & \\
\hline & \multirow{2}{*}{ 2- No Opinion } & Count & $53_{a}$ & $92_{a}$ & 145 & \\
\hline & & $\%$ within Student's major & $31.00 \%$ & $33.10 \%$ & $32.30 \%$ & \\
\hline & \multirow{2}{*}{ 3- Disagree } & Count & $76_{a}$ & $89_{b}$ & 165 & \\
\hline & & $\%$ within Student's major & $44.40 \%$ & $32.00 \%$ & $36.70 \%$ & \\
\hline \multirow{6}{*}{$\begin{array}{l}\text { Quality of library services } \\
\text { improved after accreditation }\end{array}$} & \multirow{2}{*}{ 1-Agree } & Count & $39_{a}$ & $100_{b}$ & 139 & \multirow{6}{*}{0.013} \\
\hline & & $\%$ within Student's major & $22.80 \%$ & $36.00 \%$ & $31.00 \%$ & \\
\hline & \multirow{2}{*}{ 2- No Opinion } & Count & $65_{a}$ & $90_{a}$ & 155 & \\
\hline & & $\%$ within Student's major & $38.00 \%$ & $32.40 \%$ & $34.50 \%$ & \\
\hline & \multirow{2}{*}{ 3- Disagree } & Count & $67{ }_{a}$ & $88_{a}$ & 155 & \\
\hline & & $\%$ within Student's major & $39.20 \%$ & $31.70 \%$ & $34.50 \%$ & \\
\hline
\end{tabular}

*Each subscript letter denotes a subset of Student's major categories whose column proportions do not differ significantly from each other at the .05 level. **P-value was calculated using Chi-square test

\section{CONFLICT OF INTEREST}

The authors declare no conflict of interest.

\section{ABBREVIATIONS}

ACPE: Accreditation Council for pharmacy Education; ISP: Is International Services Program BS: Bachelor of Pharmacy, Pharm D: Doctor of Pharmacy; SPSS: Statistical Package for the Social Sciences; CPD: continuing professional development.

\section{REFERENCES}

1. International Quality Criteria for Certification of Professional Degree Programs in Pharmacy. 2012. https://wwwacpe-accreditorg/pdf/ISP/ QualityCriteriapdf. 2012

2. Ariani D. Relationship model of personality, communication, student engagement, and learning satisfaction. Business, Management and Education. 2015;13(2):175-202.

3. Altbach PG, Reisberg L, Rumbley LE. Trends in global higher education: Tracking an academic revolution: Brill. 2019
4. Accreditation Standards and Guidelines A. Accreditation Council for Pharmacy Education, Accreditation Standards and Key Elements for the Professional Program in Pharmacy Leading to the Doctor of Pharmacy Degree (“Standards 2016"). 25, 2015

5. Ho MJ, Chang HH, Chiu YT, Norris JL. Effects of hospital accreditation on medical students: A national qualitative study in Taiwan. Academic Medicine. 2014;89(11):1533-9.

6. Volkwein JF, Lattuca LR, Harper BJ, Domingo RJ. Measuring the impact of professional accreditation on student experiences and learning outcomes. Research in Higher Education. 2007;48(2):251-82.

7. Draugalis JR, Plaza CM. Best practices for survey research reports revisited: Implications of target population, probability sampling and response rate. American journal of pharmaceutical education. 2009;73(8):142.

8. Fincham JE. Response rates and responsiveness for surveys, standards and the Journal. American Journal of Pharmaceutical Education. 2008;72(2):43.

9. Sealy PI, Williams S, Sa B, Ignacio DN, Extavour RM. Stakeholder perspectives on outcome expectations of pharmacy graduates from a Caribbean school of pharmacy. American journal of pharmaceutical education. 2013;77(5):99.

10. O'Brocta R, Abu-Baker A, Budukh P, Gandhi M, Lavigne J, Birnie C. A continuous professional development process for first-year pharmacy students. American Journal of Pharmaceutical Education. 2012;76(2):29.

11. Kuh GD, Hu S. The effects of student-faculty interaction in the 1990s. The Review of Higher Education. 2001;24(3):309-32. 
12. Terenzini PT, Springer L, Pascarella ET, Nora A. Academic and out-ofclass influences on students' intellectual orientations. The Review of Higher Education. 1995;19(1):23-44.

13. Vidacek-Hains V, Appatova V, Prats H. Components of effective academic learning environment: Case studies of Croatian and American students. Central European Conference on Information and Intelligent Systems: Faculty of Organization and Informatics Varazdin. 2008;1.

14. Kember D, Ho A, Hong $C$. Characterizing a teaching and learning environment capable of motivating student learning. Learning Environments Research. 2010;13(1):43-57

15. Katajavuori N, Salminen O, Vuorensola K, Huhtala H, Vuorela P, Hirvonen J. Competence-based pharmacy education in the University of Helsinki. Pharmacy. $2017 ; 5: 29$

16. Shrestha N. A study on student's use of library resources and self-efficacy: Tribhuvan University. 2008

17. Wilbur K, Paiva M, Black E. Pharmacy student and preceptor impressions of faculty liaison visits to experiential training sites. American Journal of Pharmaceutical Education. 2015;79(9):134.
18. Kim Y, Jeong KH, Kim E. A nationwide cross-sectional survey of student experiential practice at community pharmacies in South Korea. BMC Medical Education. 2019;19(1):445.

19. El-Awady ESE, Moss S, Mottram D, O'Donnell J. Student perspectives on pharmacy curriculum and instruction in Egyptian schools. American Journal of Pharmaceutical Education. 2006;70(1):09.

20. Cheng JW, Alafris A, Kirschenbaum HL, Kalis MM, Brown ME. Problembased learning versus traditional lecturing in pharmacy students' short-term examination performance. Pharmacy Education. 2003;3(2):1-9.

21. Horn DL, Neofytos D, Anaissie EJ, Fishman JA, Steinbach WJ, Olyaei AJ, et al. Epidemiology and outcomes of candidemia in 2019 patients: data from the prospective antifungal therapy alliance registry. Clinical Infectious Diseases. 2009;48(12):1695-703.

22. Alkhateeb FM, Arkle S, McDonough SL, Latif DA. Review of national and international accreditation of pharmacy programs in the gulf cooperation council countries. American journal of pharmaceutical education. 2018;82(10) 5980 .

23. Vlasses PH, Wadelin JW, Boyer JG, Travlos DV, Rouse MJ, Avery C. 2018 Annual Report of the Accreditation Council for Pharmacy Education. American journal of pharmaceutical education. 2019;83(5) 7598.

\section{PICTORIAL ABSTRACT}

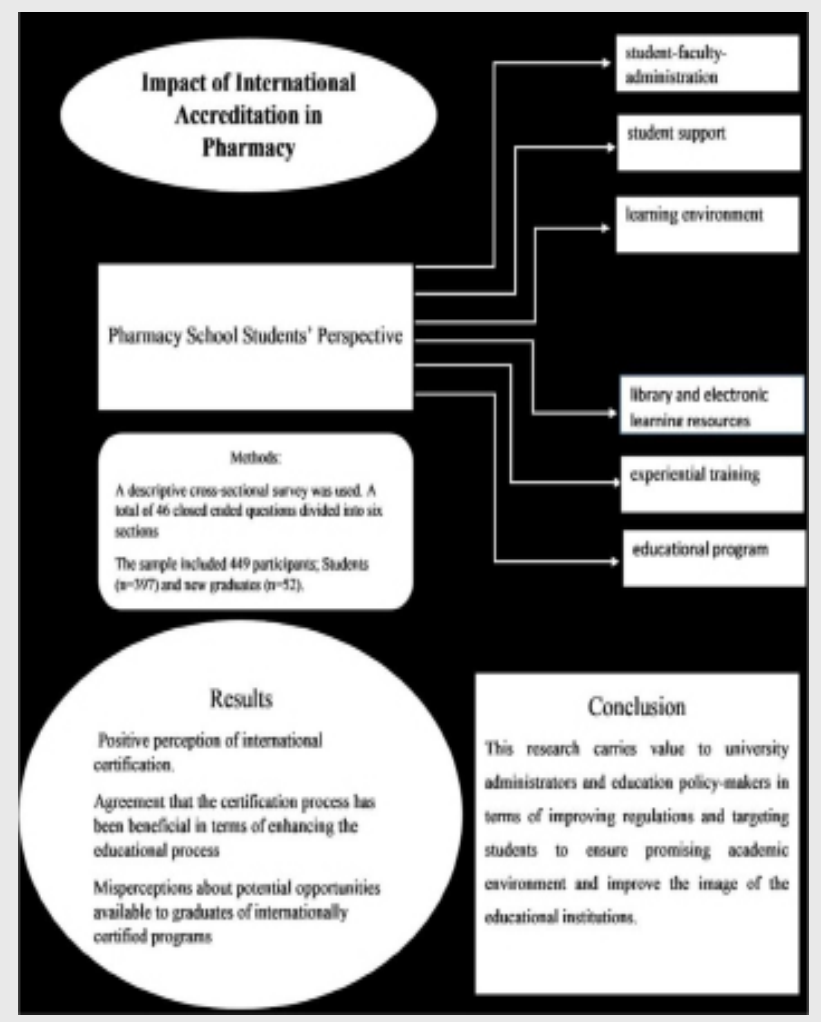

\section{About Authors}

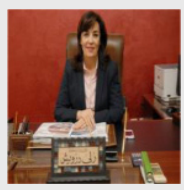

Prof. Rula M Darwish, BSc Hon., PhD, Kings'College, London, Professor in Pharmaceutical Microbiology, Former Dean of School of Pharmacy /The University of Jordan Accreditation Council for Pharmacy Education (ACPE), Advisory Group (ISPAG), Executive Committee in the Academic Section of the International Pharmaceutical Federation (FIP), The University of Jordan Queen Rania St. Amman 11942, Amman - Jordan.

Cite this article: Darwish RM, Saleh M, Ammar K, Masri MA. Impact of International Accreditation in Pharmacy Education: Pharmacy School Students' Perspective. Indian J of Pharmaceutical Education and Research. 2021;55(2s):s364-s372. 